\title{
Correction to: Does It Pay to Be Authentic? Implications of Authenticity for Life Satisfaction and Psychological Well-Being in a Collectivist Culture
}

\author{
Neerpal Rathi ${ }^{1,2}$ (D) Kidong Lee ${ }^{2}$
}

Published online: 31 March 2021

(c) Springer Nature B.V. 2021

\section{Correction to: Journal of Happiness Studies https://doi.org/10.1007/s10902-020-00223-x}

In original publication, the second affiliation of Prof. Neerpal Rathi was missed out. The correct affiliation is updated in this correction.

Funding This research was supported by Post-Doctor Research Program (2015) through Incheon National University (INU), Incheon, Republic of Korea.

Publisher's Note Springer Nature remains neutral with regard to jurisdictional claims in published maps and institutional affiliations.

The original article can be found online at https://doi.org/10.1007/s10902-020-00223-X.

Neerpal Rathi

neerpal@iimnagpur.ac.in

1 Indian Institute of Management Nagpur, VNIT Campus, South Ambazari Road, Nagpur, Maharashtra 440010, India

2 College of Business Administration, Incheon National University, Songdo-dong, South Korea 